\title{
Erosividade e padrões hidrológicos de precipitação no Agreste Central pernambucano
}

\author{
Thais E. M. dos Santos ${ }^{1}$ \& Abelardo A. A. Montenegro ${ }^{2}$
}

\begin{abstract}
RESUMO
A principal forma de erosão nas condições brasileiras é a causada pela energia cinética do impacto das gotas de chuva sobre a superfície do solo, desencadeando o processo de erosão hídrica. Desenvolveuse o presente trabalho com o objetivo de avaliar o índice de erosividade $\left(\mathrm{EI}_{30}\right)$ e caracterizar o padrão hidrológico das chuvas do Agreste Central pernambucano, considerando-se uma série de 29 anos de dados, ficando patente que o primeiro semestre do ano é caracterizado pela ocorrência de chuvas de elevado potencial erosivo. O valor do fator " $R$ " da equação universal de perda de solo para a região estudada é de $2.779,79 \mathrm{MJ} \mathrm{mm} \mathrm{ha-1} \mathrm{h}^{-1}$. O padrão de chuva de maior ocorrência é o avançado, seguido do intermediário e atrasado, com 46,57; 36,38 e $17,19 \%$ dos totais de chuvas erosivas analisados, respectivamente. Não foram encontradas correlações significativas entre erosividade, coeficiente de chuva e precipitação.
\end{abstract}

Palavras-chave: potencial erosivo das chuvas, características hidrológicas da chuva, USLE

\section{Erosivity and rainfall hydrological patterns in the Pernambuco Central 'Agreste'}

\begin{abstract}
The main form of erosion in Brazilian conditions is caused by the kinetic energy of the impact of raindrops on the soil surface, triggering the erosion process. The present study was conducted with the aim to evaluate the erosivity index (EI30), as well as to characterize the hydrological pattern of rainfall in the Pernambuco Central 'Agreste', considering a series of 29 years of data. It was found that the first half of the year is characterized by rain with high erosive potential. The value of the factor " $R$ " in the Universal equation of soil loss for the studied region is $2,779.79 \mathrm{MJ} \mathrm{mm} \mathrm{ha}{ }^{-1} \mathrm{~h}^{-1}$. The rain pattern of higher occurrence is the advanced, followed by intermediate and delayed, with $46.57 ; 36.38$ and $17.19 \%$ of total erosive rainfall analyzed, respectively. There were no significant correlations between erosivity, rainfall coefficient and precipitation.
\end{abstract}

Key words: rainfall erosive potential, rainfall hydrological characteristics, USLE 


\section{INTRODUÇÃO}

A erosão hídrica constitui um grande problema para os solos com utilização agrícola. Além da redução da produtividade das culturas, o processo erosivo pode causar sérios impactos ambientais, especialmente o assoreamento e poluição dos recursos hídricos (Cassol et al., 2007).

A erosividade das chuvas, definida como o potencial da chuva em causar erosão no solo, é função exclusivamente das características físicas da própria chuva, entre as quais são citados sua quantidade, intensidade, diâmetro de gotas, velocidade terminal e energia cinética. $\mathrm{Na}$ expectativa de detalhar os estudos desse agente erosivo, pesquisas têm demonstrado que as características da chuva que proporcionam as correlações mais elevadas com as perdas de solo são a intensidade e a energia cinética (Moreti et al., 2003).

A caracterização do fator $R$ da equação universal de perda de solo requer o cálculo do índice de erosividade das chuvas $\left(\mathrm{EI}_{30}\right)$, cujo valor é obtido pela multiplicação de dois parâmetros específicos das precipitações erosivas de dado local: energia cinética total da chuva (E) e intensidade máxima em 30 min $\left(\mathrm{I}_{30}\right)$.

Tomando-se os valores desse índice para todas as chuvas individuais erosivas que ocorrem em cada mês do ano, tem-se $\mathrm{o} \mathrm{EI}_{30}$ mensal, cuja soma caracteriza o $\mathrm{EI}_{30}$ anual. A média anual desse índice, determinada a partir de série histórica pluviográfica, representa o fator " $\mathrm{R}$ " do local em estudo.

Segundo Cassol et al. (2008), deve-se utilizar séries de registros pluviográficos de no mínimo 20 anos.

Mais de 30 anos de determinação em parcelas com coletores de enxurrada indicaram que, quando todos os demais fatores que influem na erosão, exceto a chuva, são mantidos constantes, as perdas de solo em áreas cultivadas são diretamente proporcionais ao índice $\mathrm{EI}_{30}$ (Wischmeier, 1962). Tal índice tem embasado vários estudos sobre erosividade podendo-se destacar Bazzano et al. (2010), Carvalho et al. (2009) e Cassol et al. (2008).

O conhecimento das características da chuva permite a planificação mais segura de estruturas de conservação de solo (terraços, curvas de nível) e de práticas agrícolas que visem à conservação do solo por meio de manutenção de sua cobertura, assim como outras obras (barragens, canais escoadouros) e de estruturas hidráulicas de fluxo para águas pluviais, o que justifica sua determinação (Bazzano et al., 2010).

Além da erosividade outra importante característica da chuva relacionada com o processo de erosão hídrica do solo diz respeito ao seu padrão hidrológico. Horner \& Jens (1942) caracterizaram as chuvas em padrões denominados avançados, intermediários e atrasados, quando o pico de maior intensidade da chuva ocorre, respectivamente, no primeiro terço, no segundo terço e no terceiro terço do período de duração total da chuva. No Rio Grande do Sul, Mehl et al. (2001) caracterizaram os padrões de chuva ocorrentes em Santa Maria concluindo que o padrão avançado é o que ocorre com maior frequência. Além desses autores, Bazzano et al. (2010), Carvalho et al. (2009) e Cassol et al. (2007) também adotaram a mesma metodologia de classificação dos perfis para outras regiões do Brasil.

A determinação dos valores da erosividade, ao longo do ano também permite identificar os meses nos quais os riscos de perda de solo são mais elevados, razão por que exerce relevante papel no planejamento de práticas conservacionistas fundamentadas na máxima cobertura do solo, nas épocas críticas de maior capacidade erosiva das chuvas (Dias \& Silva, 2003).

Carvalho et al. (2004) verificaram, analisando dados de chuvas e perdas de solo em São Manoel, SP, que em geral as maiores correlações do $\mathrm{EI}_{30}$ com a perda de solo foram obtidas quando as chuvas separadas por um intervalo tempo menor do que 6 horas foram tomadas como únicas e, assim sendo, foram seguidos como critério de seleção das chuvas individuais erosivas, para o cálculo da erosividade, os seguintes: considerar as chuvas maiores do que $10 \mathrm{~mm}$ e considerar a chuva menor do que $10 \mathrm{~mm}$ se ela apresentar pelo menos um segmento de intensidade que proporcione $6 \mathrm{~mm}$ em $15 \mathrm{~min}$.

Os solos da região semiárida de Pernambuco normalmente estão sujeitos a chuvas de altas intensidades ocasionando a erosão hídrica de maneira bastante severa, tornando-se necessário, portanto, estudar as características das chuvas, seus parâmetros básicos e como eles contribuem para a desagregação, transporte e deposição do solo. Deve-se ressaltar que para esta região existe carência de estudos recentes voltados para as características da precipitação e para o comportamento de seus padrões hidrológicos.

Assim, o objetivo deste trabalho é avaliar o índice de erosividade $\left(\mathrm{EI}_{30}\right)$, fornecer um valor para o fator " $\mathrm{R}$ " $\mathrm{e}$ caracterizar o padrão hidrológico das chuvas do Agreste Central pernambucano, além de sua distribuição anual.

\section{Material e MÉTODOS}

Devido à dificuldade em se obter uma série completa e com intervalo de coleta de dados que satisfaçam aos estudos de erosividade e de caracterização dos padrões hidrológicos, os dados utilizados neste trabalho pertencem a três estações vizinhas, inseridas no Agreste Central do Estado de Pernambuco. Segundo SECTMA (2006), as estações apresentam precipitação total anual média entre 550 a 700 mm.

A primeira, localizada no município de Belo Jardim, encontrase a uma latitude $08^{\circ} 20^{\prime} 08^{\prime \prime}$ Sul e a uma longitude $36^{\circ} 25^{\prime} 27^{\prime \prime}$ Oeste, estando a uma altitude de $608 \mathrm{~m}$; a segunda estação se encontra no município de Pesqueira, localizada entre $8^{\circ} 34^{\prime} 17^{\prime \prime}$ e $8^{\circ} 18^{\prime} 11^{\prime \prime}$ de latitude Sul e $37^{\circ} 1^{\prime} 35^{\prime \prime}$ e $36^{\circ} 47^{\prime} 20^{\prime \prime}$ de longitude Oeste; possui uma altitude de $654 \mathrm{~m}$; a terceira estação está localizada no município de Arcoverde, cuja altitude aproximada é de 663 m e coordenadas geográficas de $08^{\circ} 25^{\prime} 08^{\prime \prime}$ de latitude Sul e $37^{\circ} 03^{\prime}$ '14" de longitude Oeste. A maior distância entre as estações é de 72 km (SECTMA, 2006).

A estação localizada no município de Pesqueira está inserida na Bacia do Alto Ipanema, com área de $183 \mathrm{~km}^{2}$, localizada na região do Agreste Central do Estado de Pernambuco. O clima é semiárido muito quente tipo Estepe, segundo Köppen. A precipitação média anual é de $607 \mathrm{~mm}$, a temperatura média é de $23{ }^{\circ} \mathrm{C}$ e a evapotranspiração potencial é de cerca de $2.000 \mathrm{~mm}$ por ano. A vegetação predominante é a caatinga hipoxerófila (Montenegro \& Montenegro, 2006). 
A Bacia do Alto Ipanema foi escolhida em razão de integrar a rede REHISA (rede de hidrologia do semiárido), que congrega grupos de pesquisa (universidades e outras entidades) do Nordeste, atuando na região semiárida que tem, como finalidade, o desenvolvimento de pesquisas em rede para estudo dos processos hidrológicos em escala de bacias experimentais e representativas. A Bacia dispõe de estação climatológica completa, instalada em 2002, além de pluviômetros automáticos, modelo TB4-L Rain Gauge (Campbell Scientific), com resolução de 0,254 mm, programado para registrar a precipitação a cada 5 min. A partir dos dados armazenados as alturas de precipitação e a intensidade de chuva foram analisadas.

Os dados de precipitação são provenientes dos anos de 1969 a 2010, com falhas de 1977 a 1979. Os pluviógrafos convencionais funcionaram até o ano de 1993, devido à desativação da SUDENE, acarretando uma falha de 1993 a 2002. Em 2002, a UFRPE instalou pluviógrafos automáticos, da Campbell Scientific, complementando a série de 2003 a 2010. O total de dados refere-se a um período de 29 anos.

Para os cálculos da erosividade foram levados em consideração apenas as chuvas individuais.

A precipitação foi dividida por sua duração e se obteve, assim, a intensidade, dada $\mathrm{em}^{\mathrm{mm} \mathrm{h}}{ }^{-1}$, conforme Foster et al. (1981). Para determinação do índice de erosividade $\left(\mathrm{EI}_{30}\right)$, fezse necessária a multiplicação de dois parâmetros específicos das precipitações erosivas: energia cinética total da chuva (Ec), em MJ mm ha ${ }^{-1} \mathrm{~h}^{-1} \mathrm{e}$ intensidade máxima em $30 \mathrm{~min}\left(\mathrm{I}_{30}\right)$, em $\mathrm{mm} \mathrm{h}^{-1}$. De acordo com Wischmeier \& Smith (1978) e expresso nas unidades do Sistema Internacional, conforme Foster et al. (1981), foi considerada a Eq. 1 de cálculo da energia cinética por milímetro de chuva, amplamente utilizada na literatura, por Mello et al. (2007), Cassol et al. (2008), Machado et al. (2008), Carvalho et al. (2009) e Bazzano et al. (2010):

$$
\mathrm{Ec}=0,119+0,0873 \log \mathrm{I}
$$

quando $\mathrm{I} \leq 76 \mathrm{~mm} \mathrm{~h}^{-1}$, e

$$
\mathrm{Ec}=0,283
$$

quando I > $76 \mathrm{~mm} \mathrm{~h}^{-1}$, em que:

Ec - energia cinética, $\mathrm{MJ} \mathrm{ha}^{-1} \mathrm{~mm}^{-1}$

I - intensidade da chuva, $\mathrm{mm} \mathrm{h}^{-1}$

A energia cinética por incremento de chuva foi então determinada como a Eq. 2:

$$
\text { Eci }=\text { EcVol }
$$

em que:

Vol - quantidade de chuva do incremento (lâmina precipitada), $\mathrm{mm}$

Eci - energia cinética do incremento, $\mathrm{MJ} \mathrm{ha}^{-1}$

A energia cinética total foi obtida pelo somatório da energia cinética de cada incremento, segundo a Eq. 3:

$$
\mathrm{Ect}=\sum \mathrm{Eci}
$$

Logo, o $\mathrm{EI}_{30}$ foi calculado pela Eq. 4:

$$
\mathrm{EI}_{30}=\mathrm{Ect}_{30}
$$

Cada chuva foi segmentada em intervalo de $5 \mathrm{~min}$ e identificada a maior lâmina de chuva precipitada em um intervalo contínuo de $30 \mathrm{~min}$, com a qual se obteve a intensidade máxima de chuva observada nessa duração $\left(\mathrm{I}_{30}\right)$. Desta forma foi calculado, para cada precipitação, o índice $\mathrm{EI}_{30} \mathrm{em} \mathrm{MJ} \mathrm{mm} \mathrm{ha-1}^{-1}$ $\mathrm{h}^{-1}$.

Somando-se os índices $\mathrm{EI}_{30}$ de todas as chuvas individuais e erosivas de cada mês, obteve-se a erosividade mensal das chuvas e, somando-se os índices $\mathrm{EI}_{30}$ mensais, obteve-se então a erosividade anual das chuvas.

Foram determinados os padrões hidrológicos de cada chuva erosiva analisada seguindo-se a classificação proposta por Horner \& Jens (1942), que classificam as chuvas em padrões hidrológico avançado, intermediário e atrasado. Com base no padrão hidrológico de cada chuva foi calculada a percentagem do total das chuvas que representa cada padrão hidrológico.

O coeficiente de chuva foi calculado pelo método proposto por Lombardi Neto (1977), Eq. 5, dado por:

$$
\mathrm{RC}=\frac{\mathrm{Pm}^{2}}{\mathrm{~Pa}}
$$

em que:

$$
\begin{aligned}
& \mathrm{RC} \text { - coeficiente de chuva, } \mathrm{mm} \\
& \mathrm{Pm} \text { - precipitação média mensal, mm } \\
& \mathrm{Pa} \text { - precipitação média anual }
\end{aligned}
$$

Foram analisados a probabilidade de ocorrência e o correspondente período de retorno, tanto para os índices de erosividade $\mathrm{EI}_{30}$ anuais como para as chuvas máximas diárias, da série estudada.

A estimativa do período de retorno ( $\mathrm{T}$, em anos) foi calculada através da Eq. 6:

$$
\mathrm{T}=\frac{(\mathrm{N}+1)}{\mathrm{m}}
$$

em que:

$\mathrm{N}$ - representa o número de anos da série parcial

m - número de ordem, quando os eventos climatológicos são relacionados em ordem decrescente de magnitude. Desta forma, a probabilidade (Pr) inversa do período de retorno (T), pode ser calculada pela Eq. 7:

$$
\mathrm{P}=\frac{100}{\mathrm{~T}}
$$

Para avaliação das tendências temporais da erosividade nas três estações analisadas, foi utilizado o desvio normalizado, conforme a Eq. 8, como discutido por Silva et al. (2007): 


$$
\mathrm{DN}=\left(\frac{\mathrm{X}-\overline{\mathrm{X}}}{\sigma}\right) \times \mathrm{E}
$$

em que:

X - valor anual observado do elemento meteorológico

$\bar{X}$ - média do elemento meteorológico referente à série de

29 anos analisada

$\sigma$ - desvio padrão da série temporal

E - erro calculado pela Eq. 9:

$$
\mathrm{E}=\frac{\sigma}{\mathrm{X}}
$$

a partir deste erro (E) determina-se quando o ano é considerado normal $(|\mathrm{y}| \leq \mathrm{E})$; acima da média $(\mathrm{y}>\mathrm{E})$; muito acima da média $(\mathrm{y}>2 \mathrm{E})$; abaixo da média $(\mathrm{y}<-\mathrm{E})$ e muito abaixo da média $(\mathrm{y}<-2 \mathrm{E})$.

\section{RESULTADOS E DISCUSSÃO}

Durante o período de observação verificou-se a ocorrência de 481 chuvas erosivas, das quais 224 de perfil avançado, 175 de perfil intermediário e 82 de perfil atrasado, correspondendo a 46,57, 36,38 e 17,19\% do total de chuvas erosivas analisadas, respectivamente. A intensidade média dos picos foi de 50,91, 39,89 e 39,05 $\mathrm{mm} \mathrm{h}^{-1}$, para os perfis avançado, intermediário e atrasado, respectivamente.

Segundo Mehl et al. (2001), a distribuição das chuvas concentradas no padrão avançado tende a gerar menores perdas de solo pelo fato de que, no momento do pico da chuva, o solo estaria menos úmido que no caso dos outros padrões; desta forma, a desagregação, o selamento e o transporte de solo seriam menores.

O perfil avançado também foi o que apresentou maior percentual de chuvas erosivas para as localidades de Rio Grande, RS (Bazzano et al., 2010); Santa Rosa, RS (Mazurana et al., 2009); Seropédica, RJ (Carvalho et al., 2009) e São Borja, RS (Cassol et al., 2008).
Observando a Figura 1, verifica-se a distribuição de frequência de intensidade de precipitação, segundo os padrões hidrológicos avançado, intermediário e atrasado. No padrão avançado $50 \%$ dos valores são maiores que $38 \mathrm{~mm} \mathrm{~h}^{-1}$, chegando a valores de até $300 \mathrm{~mm} \mathrm{~h}^{-1}$, correspondendo a uma lâmina de $10 \mathrm{~mm}$ em $2 \mathrm{~min}$. Chuvas de alta intensidade são bem características da região. Registros semelhantes também foram observados na Bacia experimental de Sumé, localizada no Estado da Paraíba, onde precipitou uma lâmina de 9,6 mm em 2 min, gerando intensidade de $288 \mathrm{~mm} \mathrm{~h}^{-1}$ (Srinivasan \& Galvão, 2003).

Verifica-se ainda, na Figura 1, que aproximadamente 30\% das intensidades de precipitação, do padrão avançado, são valores superiores a $60 \mathrm{~mm} \mathrm{~h}^{-1}$. Santos et al. (2009) verificaram, utilizando simulador de chuvas com intensidade de precipitação de $60 \mathrm{~mm} \mathrm{~h}^{-1}$, na Bacia do Alto Ipanema, em Pesqueira, PE, que em solos descobertos as perdas de água chegam a $90 \%$ da lâmina aplicada.

No perfil atrasado, apesar de possuir menor frequência, as intensidades de precipitação, tal como no perfil avançado, atingem valores elevados chegando a $246 \mathrm{~mm} \mathrm{~h}^{-1}$. Segundo Bazzano et al. (2010), quando ocorre o pico de máxima intensidade no padrão atrasado, o solo está com maior umidade (em relação aos outros padrões), favorecendo a desagregação, o selamento superficial e o transporte das partículas de solo ocorrendo, então, maiores perdas. Enfatiza esta afirmação o estudo realizado por Carvalho et al. (2009), no município de Seropédica, RJ, buscando avaliar o efeito da erosividade e dos padrões de precipitação nas perdas de solo, constatando-se que o perfil avançado foi o que apresentou menores perdas de solo quando comparado com os perfis intermediário e atrasado.

Na Figura 2A, que representa o número de chuvas mensais, verifica-se que o padrão avançado se apresenta superior em praticamente todos os meses do ano, com exceção apenas de junho e julho, meses em que o padrão intermediário tem maior proporção. Bazzano et al. (2007) e Cassol et al. (2007) também constataram predominância ao longo do ano, do padrão avançado, para as regiões de São Borja, RS e Ijuí, RS, respectivamente.

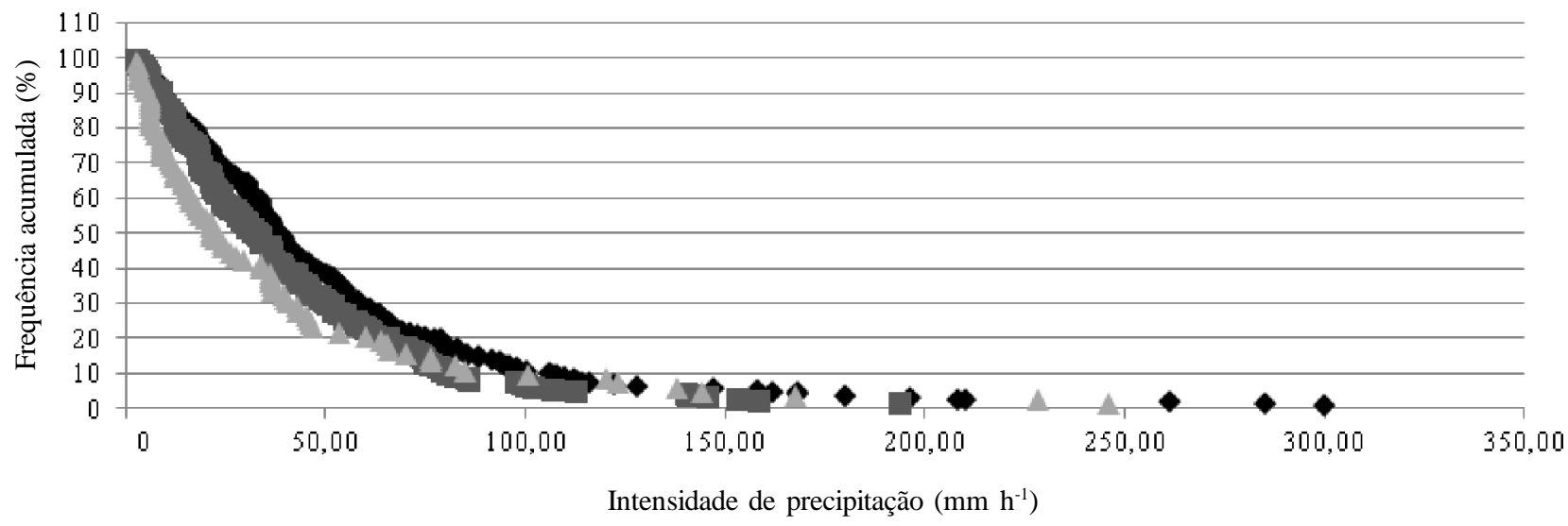

- Perfil Avançado $\quad$ Perfil Intermediário 4 Perfil Atrasado

Figura 1. Frequência acumulada dos valores de intensidade de precipitação para os padrões hidrológicos das chuvas erosivas do Agreste Central de Pernambuco de 1969 a 2010, com falhas em 1977 a 1979 e de 1993 a 2002 
A.

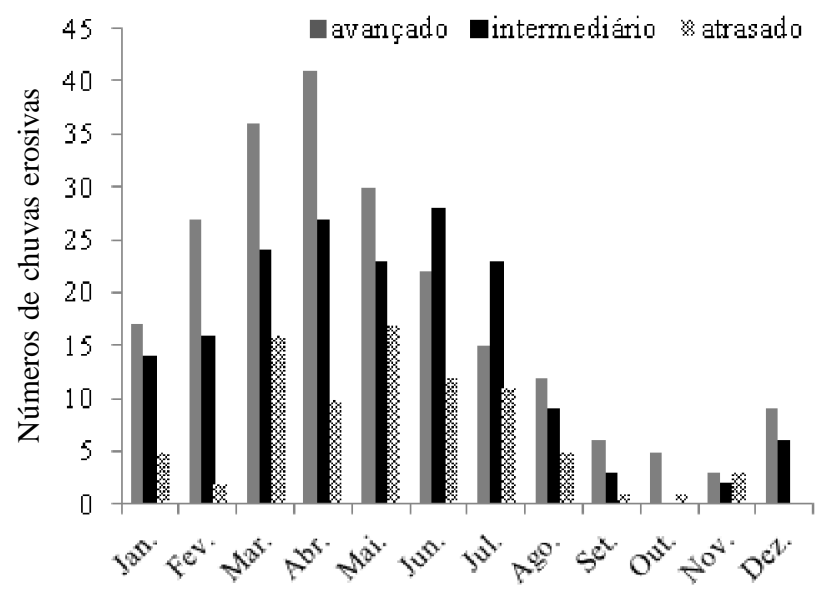

B.

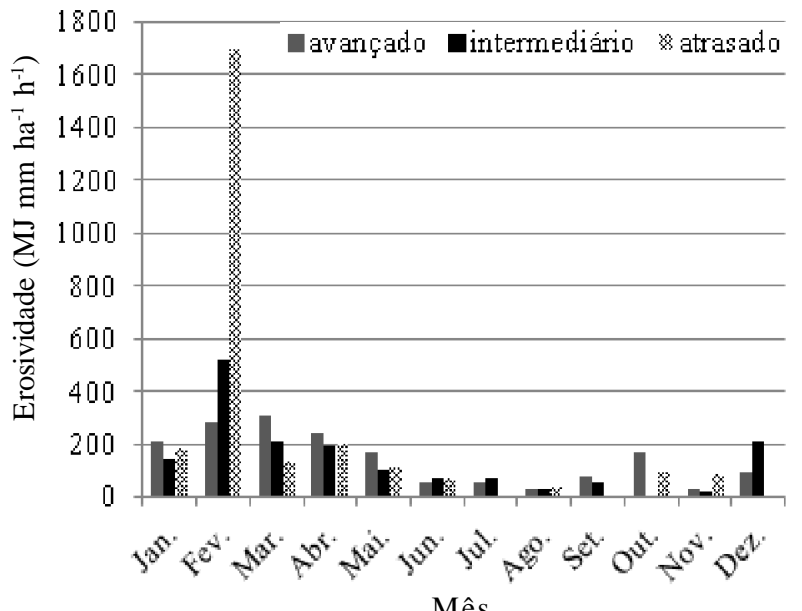

Figura 2. Distribuição do número total mensal (A) e da erosividade média mensal (B) por padrões hidrológicos das chuvas erosivas do Agreste Central de Pernambuco de 1969 a 2010, com falhas em 1977 a 1979 e de 1993 a 2002

Em referência à distribuição média mensal da erosividade das chuvas (Figura 2B) também se constata predominância do padrão avançado em quase todos os meses, com exceção do mês de fevereiro, em que a erosividade atingiu valor máximo para a série analisada, de 1693,23 $\mathrm{MJ} \mathrm{mm} \mathrm{ha}^{-1} \mathrm{~h}^{-1}$, com perfil atrasado.
Observando a Tabela 1, verifica-se que no período de 1969 a 2010 a precipitação total anual média na região, foi de 568,11 $\mathrm{mm}$. O ano de 2010 foi o de maior pluviosidade, cujo total foi de 1047,99 mm, enquanto 1981 foi o ano de menor pluviosidade, com 180,70 mm. Em relação às médias mensais, verifica-se que

Tabela 1. Valores mensais, anuais e médios mensais da precipitação pluvial ( $\mathrm{mm})$ no Agreste Central pernambucano, com as respectivas medidas estatísticas de dispersão

\begin{tabular}{|c|c|c|c|c|c|c|c|c|c|c|c|c|c|}
\hline Ano & Jan. & Fev. & Mar. & Abr. & Mai. & Jun. & Jul. & Ago. & Set. & Out. & Nov. & Dez. & Total \\
\hline 1969 & 79,00 & 106,50 & 102,70 & 45,10 & 81,60 & 31,10 & 200,40 & 18,70 & 1,60 & 0,80 & 0,00 & 13,50 & 681,00 \\
\hline 1970 & 108,30 & 44,30 & 99,70 & 58,00 & 21,60 & 17,30 & 65,40 & 28,10 & 0,00 & 24,60 & 16,90 & 9,50 & 493,70 \\
\hline 1971 & 23,30 & 10,40 & 14,80 & 115,50 & 67,80 & 46,60 & 50,50 & 3,90 & 34,50 & 18,70 & 9,90 & 0,00 & 395,90 \\
\hline 1972 & 18,30 & 33,80 & 179,20 & 117,80 & 66,60 & 105,40 & 7,40 & 68,50 & 12,00 & 7,40 & 0,00 & 25,10 & 641,50 \\
\hline 1973 & 10,20 & 0,00 & 96,70 & 129,60 & 20,20 & 47,30 & 19,50 & 4,60 & 50,20 & 15,80 & 7,00 & 0,00 & 401,10 \\
\hline 1974 & 57,60 & 130,80 & 176,20 & 5,30 & 0,00 & 0,00 & 0,00 & 0,00 & 2,60 & 0,00 & 0,00 & 0,00 & 372,50 \\
\hline 1975 & 11,90 & 3,30 & 90,80 & 163,80 & 148,80 & 79,10 & 140,20 & 11,40 & 13,40 & 0,00 & 0,00 & 0,00 & 662,70 \\
\hline 1976 & 0,00 & 90,60 & 63,70 & 165,70 & 0,00 & 0,00 & 0,00 & 0,00 & 0,00 & 0,00 & 0,00 & 0,00 & 320,00 \\
\hline 1980 & 51,50 & 67,20 & 66,50 & 22,20 & 18,00 & 93,70 & 11,10 & 3,70 & 22,20 & 35,20 & 3,80 & 8,00 & 403,10 \\
\hline 1981 & 0,00 & 0,00 & 0,00 & 31,60 & 45,60 & 12,00 & 26,50 & 24,60 & 12,40 & 0,00 & 15,00 & 13,00 & 180,70 \\
\hline 1982 & 0,00 & 66,60 & 31,00 & 71,90 & 128,70 & 33,50 & 0,00 & 0,00 & 0,00 & 0,60 & 0,00 & 8,60 & 340,90 \\
\hline 1983 & 57,00 & 67,10 & 30,80 & 3,70 & 9,90 & 57,60 & 15,70 & 0,00 & 0,00 & 0,00 & 22,50 & 0,00 & 264,30 \\
\hline 1984 & 0,00 & 7,80 & 85,60 & 273,10 & 90,00 & 29,70 & 102,10 & 0,00 & 23,50 & 1,00 & 2,20 & 12,20 & 627,20 \\
\hline 1985 & 0,00 & 104,90 & 66,60 & 152,70 & 65,10 & 100,50 & 18,20 & 0,00 & 0,80 & 0,00 & 2,60 & 41,80 & 553,20 \\
\hline 1986 & 39,70 & 90,10 & 176,60 & 107,60 & 76,00 & 67,50 & 105,80 & 41,40 & 55,40 & 0,00 & 0,00 & 0,00 & 760,10 \\
\hline 1987 & 10,00 & 44,70 & 235,90 & 49,90 & 0,00 & 55,70 & 43,50 & 13,50 & 6,90 & 22,70 & 0,00 & 4,40 & 487,20 \\
\hline 1988 & 4,20 & 77,10 & 151,50 & 93,20 & 25,20 & 56,40 & 125,70 & 11,20 & 7,00 & 5,60 & 2,10 & 94,20 & 653,40 \\
\hline 1989 & 21,60 & 0,00 & 77,30 & 102,50 & 101,10 & 87,70 & 99,00 & 28,20 & 10,80 & 14,20 & 18,20 & 128,00 & 688,60 \\
\hline 1990 & 19,80 & 25,60 & 0,00 & 0,00 & 0,00 & 0,00 & 66,60 & 30,30 & 27,30 & 23,90 & 1,80 & 4,10 & 199,40 \\
\hline 1991 & 68,30 & 7,80 & 151,60 & 87,90 & 160,50 & 33,40 & 40,00 & 65,20 & 7,00 & 4,00 & 4,50 & 0,00 & 630,20 \\
\hline 1992 & 105,20 & 117,60 & 131,80 & 25,90 & 16,30 & 44,40 & 24,80 & 8,60 & 42,90 & 0,00 & 1,60 & 1,60 & 520,70 \\
\hline 2003 & 0,00 & 89,90 & 8,64 & 0,00 & 0,00 & 99,31 & 25,15 & 0,00 & 11,68 & 0,00 & 0,00 & 0,00 & 234,68 \\
\hline 2004 & 205,74 & 159,51 & 104,14 & 6,60 & 60,45 & 150,37 & 67,56 & 42,16 & 0,00 & 0,00 & 0,00 & 0,00 & 796,54 \\
\hline 2005 & 35,06 & 57,91 & 140,97 & 29,97 & 201,94 & 197,62 & 71,12 & 138,18 & 13,72 & 0,00 & 0,76 & 127,25 & 1014,48 \\
\hline 2006 & 4,83 & 88,92 & 39,37 & 113,79 & 176,79 & 116,84 & 38,35 & 219,46 & 86,36 & 12,95 & 1,27 & 2,03 & 900,97 \\
\hline 2007 & 0,00 & 0,00 & 0,00 & 65,79 & 68,33 & 113,03 & 33,53 & 55,12 & 16,76 & 0,00 & 0,00 & 0,00 & 352,56 \\
\hline 2008 & 12,95 & 37,08 & 212,08 & 122,43 & 198,88 & 53,34 & 82,55 & 46,74 & 0,00 & 0,00 & 0,00 & 48,26 & 814,32 \\
\hline 2009 & 120,65 & 115,06 & 10,41 & 210,57 & 260,86 & 70,87 & 78,49 & 68,33 & 0,00 & 43,18 & 25,40 & 32,51 & 1036,33 \\
\hline 2010 & 122,94 & 134,10 & 91,95 & 233,43 & 0,00 & 235,20 & 35,81 & 11,18 & 46,48 & 103,12 & 0,00 & 33,78 & 1047,99 \\
\hline Média & 40,97 & 61,33 & 90,92 & 89,85 & 72,77 & 70,19 & 55,00 & 32,52 & 17,43 & 11,51 & 4,67 & 20,96 & 568,11 \\
\hline DP & 50,48 & 47,55 & 67,06 & 72,68 & 72,50 & 55,83 & 47,67 & 47,46 & 21,19 & 21,26 & 7,48 & 36,05 & 250,16 \\
\hline CV (\%) & 1,23 & 0,78 & 0,74 & 0,81 & 1,00 & 0,80 & 0,87 & 1,46 & 1,22 & 1,85 & 1,60 & 1,72 & 0,44 \\
\hline Máx. & 205,74 & 159,51 & 235,90 & 273,10 & 260,86 & 235,20 & 200,40 & 219,46 & 86,36 & 103,12 & 25,40 & 128,00 & 1047,99 \\
\hline Mín. & 0,00 & 0,00 & 0,00 & 0,00 & 0,00 & 0,00 & 0,00 & 0,00 & 0,00 & 0,00 & 0,00 & 0,00 & 180,70 \\
\hline
\end{tabular}

DP - desvio padrão; CV- coeficiente de variação; Máx.- valor máximo da série. Mín. - valor mínimo da série 
o mês de março apresentou maior média, com 90,92 mm, enquanto o mês de novembro indicou a menor média, com valor de 4,67 mm. A pluviosidade média mensal, variando de 4,67 a 90,92 mm, resulta da heterogeneidade temporal da distribuição da precipitação na região semiárida de Pernambuco que, como constatado por Santos et al. (2010), caracteriza-se pela má distribuição no tempo e no espaço, apresentando um período de estiagem que ocorre de setembro a fevereiro e um período chuvoso, de março a agosto, representado por chuvas de alta intensidade e de curta duração, resultando em elevado risco de perda de água e solo.

Na Figura 3 se observam os dados de erosividade médios mensais para os 29 anos estudados, verificando-se que o maior índice de erosividade se concentra nos meses de fevereiro a abril, os quais também possuem maiores valores discrepantes; já nos demais meses a erosividade das chuvas é muito baixa, chegando a zero em alguns meses, indicando que no primeiro semestre os riscos de erosão são maiores. Salienta-se que, na região do Agreste Central de Pernambuco, o primeiro semestre é o período em que ocorre o preparo do solo para a prática da agricultura de sequeiro requerendo, assim, adoção de técnicas de conservação; porém, deve-se adotar medidas conservacionistas durante todo o ano visto que em anos atípicos as chuvas ocorridas no verão podem acarretar processos erosivos, já que tais chuvas se apresentam com alta intensidade e curta duração, conforme constatado.

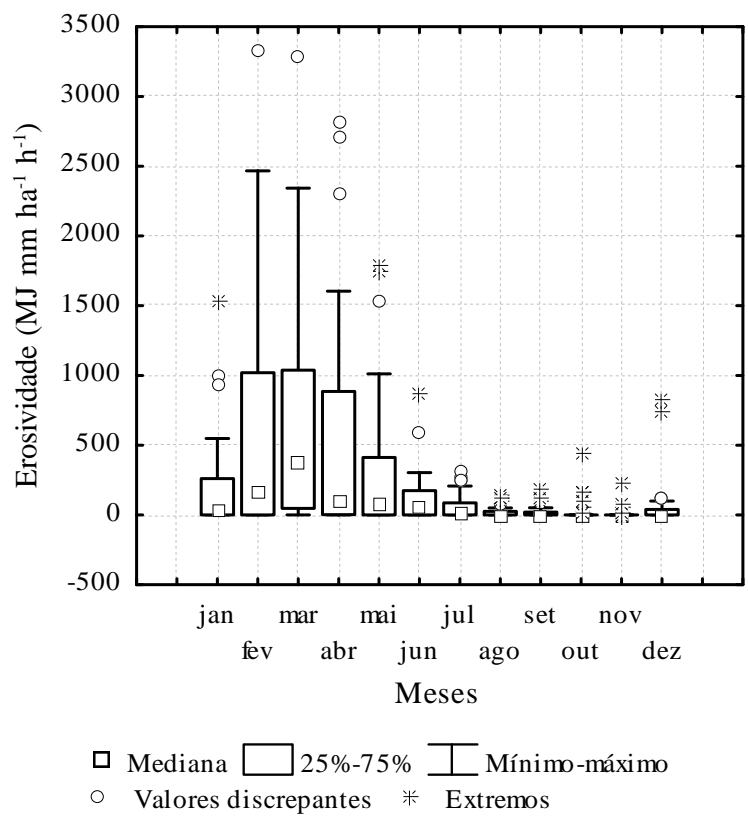

Figura 3. Box-plot dos valores médios mensais do índice de erosividade $\left(\mathrm{EI}_{30}\right)$ no Agreste Central de Pernambuco de 1969 a 2010, com falhas em 1977 a 1979 e de 1993 a 2002

Na Figura 4 observa-se a distribuição anual do índice de erosividade, verificando-se que a distribuição ao longo dos anos não é regular. Observando o boxplot, pode-se inferir que os anos de 1986, 2009 e 2010 possuem maior mediana concluindo-se, então, que os referidos anos possuem maiores valores de erosividade, distribuídos ao longo do ano, em relação aos demais. Tem-se, ainda nesta figura, que os anos de 1975, 1985, 1986, 1988, 1989, 2004 e de 2008 a 2010 possuem maior dispersão já que os valores mínimo-máximo são mais acentuados em relação aos demais.

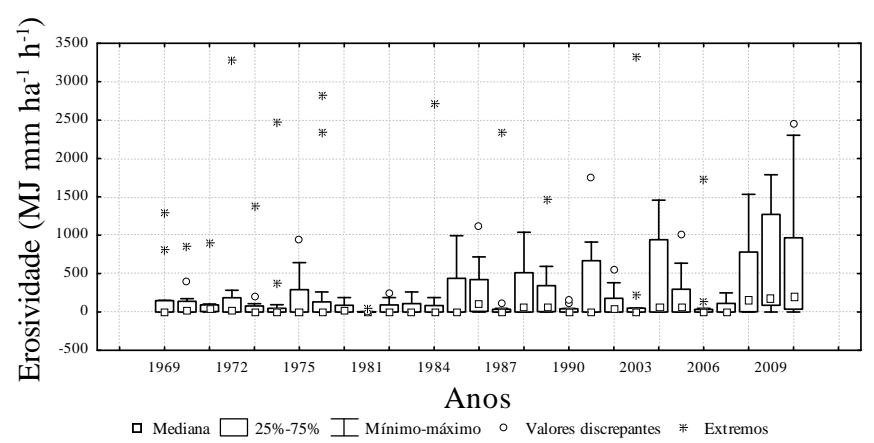

Figura 4. Distribuição anual do índice de erosividade $\left(\mathrm{EI}_{30}\right)$ no Agreste Central de Pernambuco de 1969 a 2010, com falhas em 1977 a 1979 e de 1993 a 2002

Na Figura 5 observa-se a série temporal do desvio normalizado para as erosividades anuais. Durante o período estudado não se verificaram anos com erosividades muito acima ou muito abaixo da média, com exceção para os anos atípicos de 2009 e 2010.

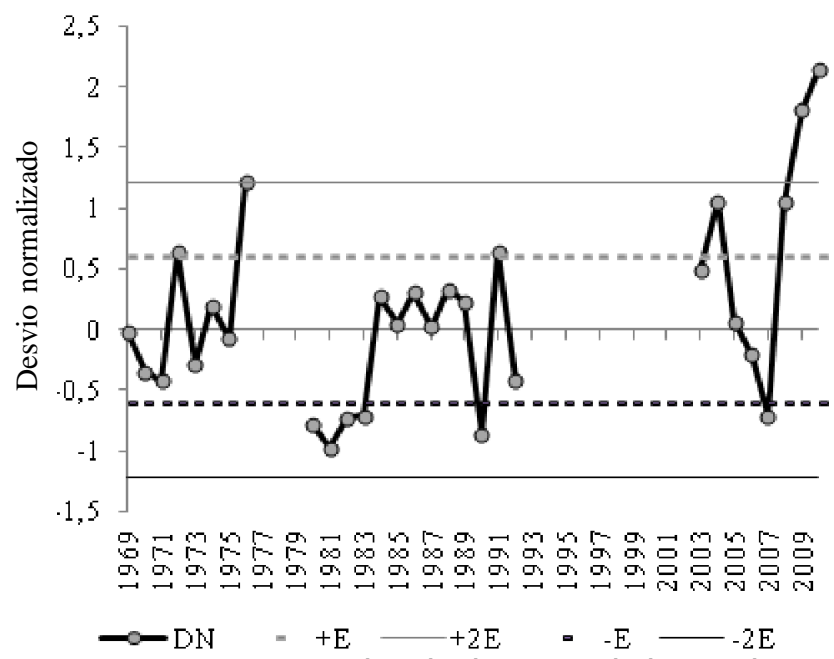

Figura 5. Desvio normalizado da erosividade anual para o Agreste Central de Pernambuco de 1969 a 2010, com falhas em 1977 a 1979 e de 1993 a 2002

Com base na Tabela 2, verifica-se que a erosividade média anual para a região Agreste Central do estado de Pernambuco é de $2.779,79 \mathrm{MJ} \mathrm{mm} \mathrm{ha}{ }^{-1} \mathrm{~h}^{-1}$ valor que representa o fator " $\mathrm{R}$ " da equação universal de perda de solo, podendo ser utilizado para a região estudada. Quanto à média mensal observa-se variação de $12,67 \mathrm{MJ} \mathrm{mm} \mathrm{ha}^{-1} \mathrm{~h}^{-1}$, no mês de novembro a 666,44 MJ mm ha ${ }^{-1} h^{-1}$, no mês de fevereiro.

Referente aos valores médios anuais, os extremos foram de $640 \mathrm{MJ} \mathrm{mm} \mathrm{ha}^{-1} \mathrm{~h}^{-1}$, para o ano de 2010 e de $4,97 \mathrm{MJ} \mathrm{mm} \mathrm{ha}^{-1} \mathrm{~h}^{-1}$, para o ano de 1981 .

$\mathrm{O}$ valor de $2.779,79 \mathrm{MJ} \mathrm{mm} \mathrm{ha}^{-1} \mathrm{~h}^{-1}$ é considerado de erosividade média, de acordo com a classificação proposta por Carvalho (2008), representada pela Tabela 3. 
Tabela 2. Valores mensais, anuais e médios mensais do índice de erosividade $\mathrm{El}_{30}\left(\mathrm{MJ} \mathrm{mm} \mathrm{ha-1} \mathrm{h}^{-1}\right)$ no Agreste Central pernambucano, com as respectivas medidas estatísticas de dispersão

\begin{tabular}{|c|c|c|c|c|c|c|c|c|c|c|c|c|c|}
\hline Ano & Jan. & Fev. & Mar. & Abr. & Mai. & Jun. & Jul. & Ago. & Set. & Out. & Nov. & Dez. & Total \\
\hline 1969 & 152,07 & 1289,62 & 142,24 & 0,00 & 815,01 & 0,00 & 0,00 & 0,00 & 0,00 & 0,00 & 0,00 & 0,00 & 2398,94 \\
\hline 1970 & 392,27 & 21,35 & 858,10 & 104,32 & 0,00 & 0,00 & 12,17 & 25,94 & 0,00 & 173,12 & 10,70 & 0,00 & 1597,97 \\
\hline 1971 & 103,59 & 11,18 & 32,72 & 905,64 & 92,90 & 91,97 & 87,95 & 0,00 & 21,04 & 64,82 & 0,00 & 0,00 & 1411,81 \\
\hline 1972 & 0,00 & 0,00 & 3280,67 & 282,45 & 29,99 & 265,18 & 0,00 & 106,62 & 0,00 & 0,00 & 0,00 & 40,20 & 4005,10 \\
\hline 1973 & 197,89 & 0,00 & 1380,87 & 107,53 & 0,00 & 12,13 & 0,00 & 0,00 & 50,20 & 0,00 & 0,00 & 0,00 & 1748,62 \\
\hline 1974 & 94,81 & 2466,83 & 365,92 & 0,00 & 0,00 & 0,00 & 0,00 & 0,00 & 0,00 & 0,00 & 0,00 & 0,00 & 2927,56 \\
\hline 1975 & 0,00 & 0,00 & 373,10 & 951,61 & 643,14 & 94,21 & 207,16 & 0,00 & 0,00 & 0,00 & 0,00 & 0,00 & 2269,23 \\
\hline 1976 & 0,00 & 2336,49 & 261,31 & 2823,74 & 0,00 & 0,00 & 0,00 & 0,00 & 0,00 & 0,00 & 0,00 & 0,00 & 5421,54 \\
\hline 1980 & 41,40 & 147,46 & 51,47 & 10,74 & 0,00 & 78,11 & 0,00 & 0,00 & 188,02 & 6,04 & 0,00 & 0,00 & 523,24 \\
\hline 1981 & 0,00 & 0,00 & 0,00 & 0,00 & 43,32 & 0,00 & 10,82 & 4,36 & 0,00 & 0,00 & 1,20 & 0,00 & 59,70 \\
\hline 1982 & 0,00 & 188,04 & 133,18 & 49,86 & 237,52 & 46,34 & 0,00 & 0,00 & 0,00 & 0,00 & 0,00 & 0,00 & 654,94 \\
\hline 1983 & 260,76 & 85,70 & 0,00 & 0,00 & 0,00 & 131,30 & 0,00 & 0,00 & 0,00 & 0,00 & 220,00 & 0,00 & 697,75 \\
\hline 1984 & 0,00 & 0,00 & 187,72 & 2705,47 & 81,37 & 0,00 & 87,04 & 0,00 & 0,00 & 0,00 & 0,00 & 41,55 & 3103,14 \\
\hline 1985 & 0,00 & 457,73 & 591,00 & 993,24 & 418,23 & 12,67 & 0,00 & 0,00 & 0,00 & 0,00 & 0,00 & 99,28 & 2572,16 \\
\hline 1986 & 429,73 & 717,50 & 1121,20 & 215,42 & 412,83 & 15,93 & 240,64 & 14,32 & 27,15 & 0,00 & 0,00 & 0,00 & 3194,73 \\
\hline 1987 & 0,00 & 74,41 & 2343,54 & 2,65 & 0,00 & 20,28 & 22,92 & 0,00 & 0,00 & 0,00 & 46,59 & 0,00 & 2510,39 \\
\hline 1988 & 0,00 & 844,08 & 1038,62 & 210,60 & 56,42 & 82,09 & 277,15 & 0,00 & 0,00 & 0,00 & 0,00 & 745,74 & 3254,69 \\
\hline 1989 & 87,93 & 0,00 & 1470,38 & 408,15 & 278,13 & 593,47 & 55,16 & 8,14 & 0,00 & 0,00 & 10,62 & 97,25 & 3009,23 \\
\hline 1990 & 36,96 & 0,00 & 0,00 & 0,00 & 0,00 & 0,00 & 105,48 & 0,00 & 45,51 & 158,58 & 0,00 & 0,00 & 346,53 \\
\hline 1991 & 450,30 & 0,00 & 911,06 & 885,75 & 1748,23 & 0,00 & 8,93 & 22,04 & 0,00 & 0,00 & 0,00 & 0,00 & 4026,31 \\
\hline 1992 & 548,27 & 247,14 & 380,80 & 57,03 & 17,64 & 56,63 & 0,00 & 0,00 & 108,78 & 0,00 & 0,00 & 0,00 & 1416,30 \\
\hline 2003 & 0,00 & 3322,34 & 46,76 & 0,00 & 0,00 & 212,48 & 6,12 & 0,00 & 51,04 & 0,00 & 0,00 & 0,00 & 3638,74 \\
\hline 2004 & 1005,65 & 1456,74 & 1130,89 & 21,78 & 390,50 & 876,41 & 64,41 & 75,33 & 0,00 & 0,00 & 0,00 & 0,00 & 5021,71 \\
\hline 2005 & 213,31 & 287,89 & 635,33 & 0,00 & 1011,96 & 303,45 & 16,72 & 129,31 & 0,00 & 0,00 & 0,00 & 0,00 & 2597,97 \\
\hline 2006 & 0,00 & 1738,41 & 0,00 & 21,22 & 136,28 & 46,29 & 0,00 & 0,00 & 0,00 & 0,00 & 0,00 & 0,00 & 1942,20 \\
\hline 2007 & 0,00 & 0,00 & 0,00 & 249,23 & 172,63 & 173,84 & 35,75 & 49,60 & 20,93 & 0,00 & 0,00 & 0,00 & 701,97 \\
\hline 2008 & 35,72 & 162,80 & 1277,13 & 726,27 & 1532,67 & 5,18 & 309,48 & 132,63 & 0,00 & 0,00 & 0,00 & 836,16 & 5018,05 \\
\hline 2009 & 1523,03 & 1019,80 & 7,71 & 1604,29 & 1787,89 & 248,47 & 257,75 & 113,96 & 0,00 & 95,24 & 78,46 & 124,13 & 6860,72 \\
\hline 2010 & 933,70 & 2451,37 & 998,29 & 2302,43 & 0,00 & 253,30 & 21,07 & 50,30 & 128,26 & 432,52 & 0,00 & 111,37 & 7682,61 \\
\hline Média & 224,39 & 666,44 & 655,86 & 539,29 & 341,61 & 124,82 & 62,99 & 25,26 & 22,10 & 32,08 & 12,67 & 72,26 & 2779,79 \\
\hline DP & 368,01 & 949,37 & 778,66 & 827,79 & 535,23 & 197,13 & 96,61 & 43,21 & 45,62 & 89,77 & 43,22 & 203,04 & 1388,95 \\
\hline CV (\%) & 1,64 & 1,42 & 1,19 & 1,53 & 1,57 & 1,58 & 1,53 & 1,71 & 2,06 & 2,80 & 3,41 & 2,81 & 0,50 \\
\hline Máx. & 1523,03 & 3322,34 & 3280,67 & 2823,74 & 1787,89 & 876,41 & 309,48 & 132,63 & 188,02 & 432,52 & 220,00 & 836,16 & 7682,61 \\
\hline Mín. & 0,00 & 0,00 & 0,00 & 0,00 & 0,00 & 0,00 & 0,00 & 0,00 & 0,00 & 0,00 & 0,00 & 0,00 & 59,70 \\
\hline
\end{tabular}

DP: desvio padrão; CV: coeficiente de variação; Máx.: valor máximo da série. Mín.: valor mínimo da série

Tabela 3. Classe para interpretação do índice de erosividade anual

\begin{tabular}{ll}
\hline \multicolumn{1}{c}{ Erosividade (MJ $\mathbf{~ m m ~} \mathbf{~ h a ~ h}^{-1}$ ) } & \multicolumn{1}{c}{ Classe de erosividade } \\
$\mathrm{R} \leq 2452$ & Erosividade fraca \\
$2452<\mathrm{R} \leq 4905$ & Erosividade moderada \\
$4905<\mathrm{R} \leq 7357$ & Erosividade moderada a forte \\
$7357<\mathrm{R} \leq 9810$ & Erosividade forte \\
$\mathrm{R}>9810$ & Erosividade muito forte \\
\hline Fonte: Carvalho (2008) &
\end{tabular}

A erosividade média anual mostrou-se abaixo das médias anuais encontradas por Dias \& Silva (2003) em Fortaleza, CE (6.774 MJ mm ha ${ }^{-1} \mathrm{~h}^{-1}$ ), Maia Neto \& Chaves (1997), no Estado da Paraíba (2.000 a 8.000 MJ mm ha ${ }^{-1} \mathrm{~h}^{-1}$ ), Rufino et al. (1993), no Estado do Paraná (5.500 a $12.000 \mathrm{MJ}^{\mathrm{mm} \mathrm{ha}} \mathrm{h}^{-1} \mathrm{~h}^{-1}$ ) e Bertoni \& Lombardi Neto (1990), no litoral do Estado de São Paulo (6.000 a 7.500 MJ mm ha ${ }^{-1} \mathrm{~h}^{-1}$ ).

Quando comparada com valores encontrados para o Agreste pernambucano, nota-se que a média anual de $2.779,79 \mathrm{MJ} \mathrm{mm}$ $\mathrm{ha}^{-1} \mathrm{~h}^{-1}$ fica próxima às encontradas por Albuquerque et al. (1994) (2.100 MJ mm ha ${ }^{-1} \mathrm{~h}^{-1}$ ) e Margolis et al. (1985) (2.060 MJ $\mathrm{mm} \mathrm{ha}^{-1} \mathrm{~h}^{-1}$ ), ambos em Caruaru, PE. Silva et al. (1985) encontraram, buscando caracterizar o índice de erosividade para as regiões Agreste e Sertão do Estado de Pernambuco, valores médios anuais de $2.775,5$ e de $3.699,28 \mathrm{MJ} \mathrm{mm} \mathrm{ha}^{-1} \mathrm{~h}^{-1}$, respectivamente. Lopes \& Brito (1993) encontraram valor de 3.772 $\mathrm{MJ} \mathrm{mm} \mathrm{ha}^{-1} \mathrm{~h}^{-1}$ para a região do Médio São Francisco no polo Petrolina, PE - Juazeiro, BA, localizado no Sertão do Estado.

Por outro lado e comparada com outros autores, a média anual encontrada neste trabalho, de $2.779,79 \mathrm{MJ} \mathrm{mm} \mathrm{ha}^{-1} \mathrm{~h}^{-1}$, mantém-se inferior aos valores encontrados por Albuquerque et al. (2001), em Sumé, PB (4.298 MJ mm ha-1 $\left.\mathrm{h}^{-1}\right)$ e Campos Filho et al. (1992), no Agreste pernambucano (3.551 $\mathrm{MJ} \mathrm{mm} \mathrm{ha}^{-1}$ $\left.\mathrm{h}^{-1}\right)$, embora ambas as erosividades possam ser classificadas como erosividade moderada. Já Chaves et al. (1997) encontraram em Patos, PB, valor de $5.200 \mathrm{MJ} \mathrm{mm} \mathrm{ha}{ }^{-1} \mathrm{~h}^{-1}$, devendo tal erosividade ser classificada como moderada a forte, conforme Carvalho (2008). A grande variabilidade espacial do fator erosividade no Brasil é natural, decorrente da variabilidade climática entre as diversas regiões do País, indicando grande variabilidade no risco de erosão hídrica.

A Figura 6 apresenta a frequência acumulada dos valores totais anuais do índice de erosividade $\left(\mathrm{EI}_{30}\right)$. Verifica-se que os valores foram bem diversos, com mínimo de 59,70 MJ mm ha $^{-1} \mathrm{~h}^{-1}$, para o ano de 1981, o qual também apresentou menor pluviosidade (Tabela 1) e o valor máximo de erosividade que ocorreu no ano de 2010, com valor de 7682,61 $\mathrm{MJ} \mathrm{mm} \mathrm{ha}^{-1} \mathrm{~h}^{-1}$. 


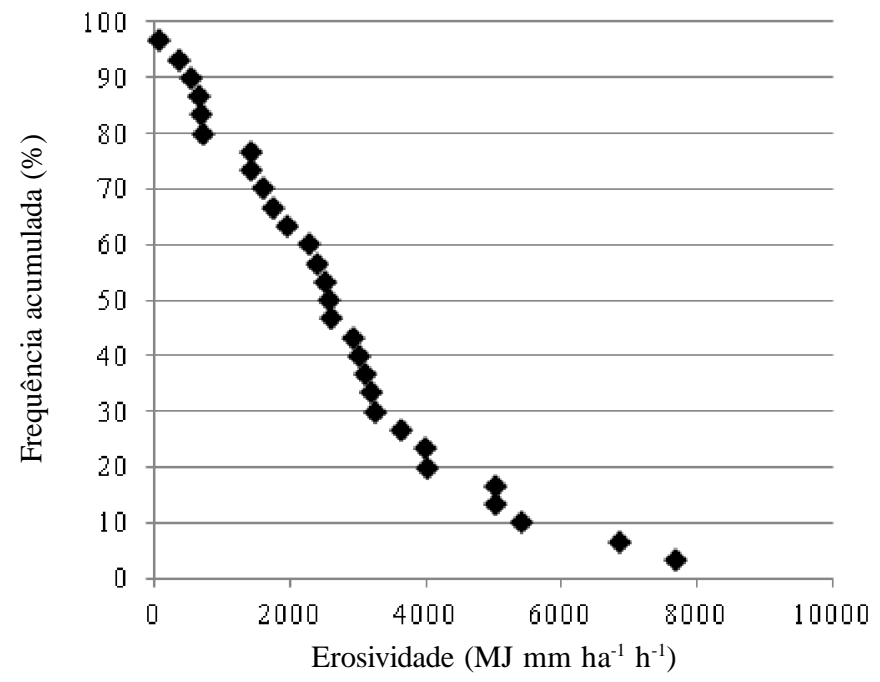

Figura 6. Frequência acumulada (\%) dos totais anuais do índice de erosividade $\left(\mathrm{EI}_{30}\right)$ para o Agreste Central de Pernambuco no período de 1969 a 2010, com falhas em 1977 a 1979 e de 1993 a 2002

Na Figura 7 estão as correlações entre o índice de erosividade médio mensal e o coeficiente de chuva (Figura 7A) e entre o índice de erosividade médio mensal e a precipitação (Figura 7B). Para o índice de erosividade e o coeficiente de chuva, a

A.

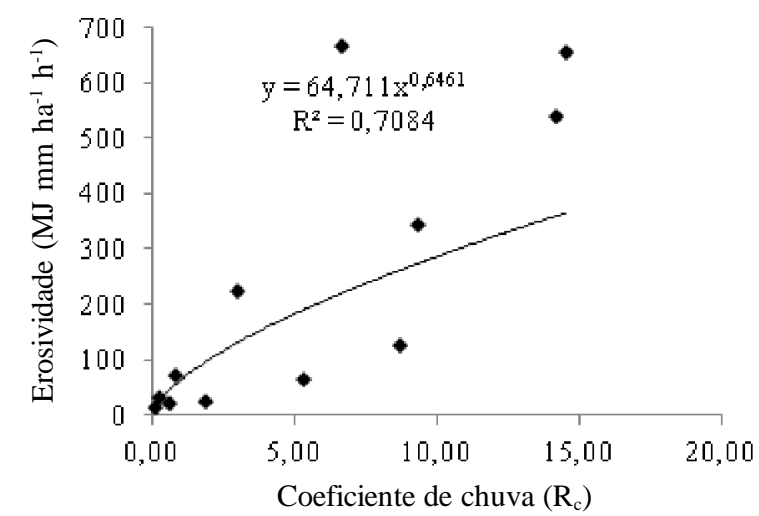

B.

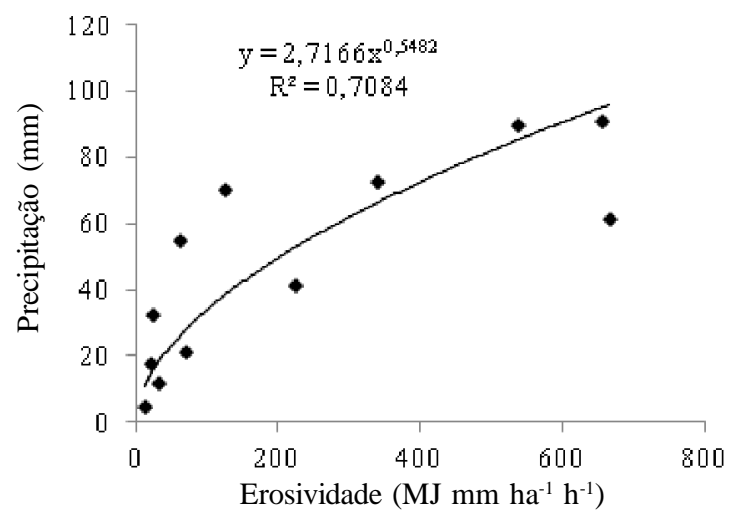

Figura 7. Relação entre o índice de erosividade médio mensal e o coeficiente de chuva (A) e o índice de erosividade médio mensal e a precipitação (B), no Agreste Central de Pernambuco de 1969 a 2010, com falhas em 1977 a 1979 e de 1993 a 2002 linha de tendência ajustada foi do tipo potência, com coeficiente de determinação de 0,71 , não apresentando uma correlação elevada quando comparada com coeficientes de determinação de 0,91 obtida por Almeida et al. (2011), para Cuiabá, MT, determinação de 0,84, obtida por Cassol et al. (2008), para São Borja, RS, e de 0,96, obtida por Colodro et al. (2002), para Teodoro Sampaio (SP). Também não foram encontradas correlações significativas entre o índice de erosividade e o coeficiente de chuva por Bazzano et al. (2010), para o município de Rio Grande, RS, enquanto Cassol et al. (2007) encontraram $\mathrm{R}^{2}$ de apenas 0,53 , para o município de Ijuí, $\mathrm{RS}$.

A relação entre o índice de erosividade médio mensal e a precipitação também apresentou ajuste tipo potência com $\mathrm{R}^{2}$ de 0,71 . Baixas correlações entre essas duas variáveis também foram encontradas por Bazzano et al. (2010), enquanto Almeida et al. (2011) encontraram $\mathrm{R}^{2}$ de 0,91 para essas duas variáveis.

$\mathrm{Na}$ Tabela 4 se apresentam o período de retorno e a probabilidade de ocorrência dos valores dos índices anuais de erosividade, durante o período de1969 a 2010. Observa-se que o valor do período de retorno e da probabilidade de ocorrência determinada para o maior índice de erosividade anual observado (7.138,72 $\mathrm{MJ} \mathrm{mm} \mathrm{ha}^{-1} \mathrm{~h}^{-1}$ ) foi, respectivamente, de 30,0 anos e $3,33 \%$. Da mesma forma, os valores para a menor erosividade $\left(59,70 \mathrm{MJ} \mathrm{mm} \mathrm{ha}^{-1} \mathrm{~h}^{-1}\right)$ foram de 1,03 anos e de 96,67\%.

Tabela 4. Período de retorno e probabilidade de ocorrência dos valores do índice de erosividade (MJ mm ha $\left.{ }^{-1} \mathrm{~h}^{-1}\right)$, no período de 1969 a 2010, com falhas nos anos de 1977 a 1979 e 1993 a 2002

\begin{tabular}{rccccc}
\hline Ano & Total & $\begin{array}{c}\text { Número de } \\
\text { ordem }(\mathbf{m})\end{array}$ & $\begin{array}{c}\text { Período de } \\
\text { retorno (T) }\end{array}$ & $\begin{array}{c}\text { Probabilidade de } \\
\text { ocorrência (Pr) }\end{array}$ & Frequência \\
\hline 2010 & 7682,61 & 1 & 30,00 & 3,33 & 3,33 \\
2009 & 6860,72 & 2 & 15,00 & 6,67 & 6,67 \\
1976 & 5421,54 & 3 & 10,00 & 10,00 & 10,00 \\
2004 & 5021,71 & 4 & 7,50 & 13,33 & 13,33 \\
2008 & 5018,05 & 5 & 6,00 & 16,67 & 16,67 \\
1991 & 4026,31 & 6 & 5,00 & 20,00 & 20,00 \\
1972 & 4005,10 & 7 & 4,29 & 23,33 & 23,33 \\
2003 & 3638,74 & 8 & 3,75 & 26,67 & 26,67 \\
1988 & 3254,69 & 9 & 3,33 & 30,00 & 30,00 \\
1986 & 3194,73 & 10 & 3,00 & 33,33 & 33,33 \\
1984 & 3103,14 & 11 & 2,73 & 36,67 & 36,67 \\
1989 & 3009,23 & 12 & 2,50 & 40,00 & 40,00 \\
1974 & 2927,56 & 13 & 2,31 & 43,33 & 43,33 \\
2005 & 2597,97 & 14 & 2,14 & 46,67 & 46,67 \\
1985 & 2572,16 & 15 & 2,00 & 50,00 & 50,00 \\
1987 & 2510,39 & 16 & 1,88 & 53,33 & 53,33 \\
1969 & 2398,94 & 17 & 1,76 & 56,67 & 56,67 \\
1975 & 2269,23 & 18 & 1,67 & 60,00 & 60,00 \\
2006 & 1942,20 & 19 & 1,58 & 63,33 & 63,33 \\
1973 & 1748,62 & 20 & 1,50 & 66,67 & 66,67 \\
1970 & 1597,97 & 21 & 1,43 & 70,00 & 70,00 \\
1992 & 1416,30 & 22 & 1,36 & 73,33 & 73,33 \\
1971 & 1411,81 & 23 & 1,30 & 76,67 & 76,67 \\
2007 & 701,97 & 24 & 1,25 & 80,00 & 80,00 \\
1983 & 697,75 & 25 & 1,20 & 83,33 & 83,33 \\
1982 & 654,94 & 26 & 1,15 & 86,67 & 86,67 \\
1980 & 523,24 & 27 & 1,11 & 90,00 & 90,00 \\
1990 & 346,53 & 28 & 1,07 & 93,33 & 93,33 \\
1981 & 59,70 & 29 & 1,03 & 96,67 & 96,67 \\
\hline & & & & & \\
\hline
\end{tabular}


Prevê-se que o valor médio anual de erosividade, 2.779,79 (MJ mm ha-1 $\mathrm{h}^{-1}$ ) ocorra a, aproximadamente, cada 2,23 anos, com probabilidade de $42,49 \%$.

\section{CONClusÕES}

1. O padrão de chuva de maior ocorrência no Agreste Central pernambucano é o avançado, seguido dos intermediário e atrasado, com 46,57, 36,38 e 17,19\% dos totais de chuvas erosivas analisados, respectivamente.

2. Não foi encontrada correlação significativa entre erosividade e coeficiente de chuva nem, tampouco, com a precipitação.

3. O primeiro semestre do ano é caracterizado pela ocorrência de chuvas de elevado potencial erosivo, sendo os meses de fevereiro e março aqueles que apresentaram maiores erosividades.

4. Espera-se que o valor médio anual de erosividade, $2.779,79$ (MJ mm ha-1 $\mathrm{h}^{-1}$ ) ocorra, aproximadamente, a cada 2,23 anos, com probabilidade de $42,49 \%$, podendo ser classificada como moderada.

\section{Agradecimentos}

Os autores agradecem à FINEP, ao CNPq e à CAPES/ FACEPE, pelo apoio financeiro.

\section{LITERATURA CITADA}

Albuquerque, A.W.; Chaves, I. B.; Vasques Filho, J. Distribuição e relações com a precipitação pluviométrica de Caruaru-PE. Revista Brasileira de Engenharia Agrícola, v. 14, p.83-90. 1994.

Albuquerque, A.W.; Lombardi Neto, F.; Srinivasan, V. S. Efeito do desmatamento da caatinga sobre as perdas de solo e água de um Luvissolo em Sumé (PB). Revista Brasileira de Ciência do Solo, v.25, p.121-128. 2001.

Almeida, C. O. S.; Amorim, R. S. S.; Couto, E. G.; Eltz, F. L. F.; Borges, L. E. C. Potencial erosivo da chuva de Cuiabá, MT: Distribuição e correlação com a precipitação pluviométrica. Revista Brasileira de Engenharia Agrícola e Ambiental, v.15, p.178-184, 2011.

Bazzano, M. G. P.; Eltz, F. L. F.; Cassol, E. A. Erosividade, coeficiente de chuva, padrões e período de retorno das chuvas de Quaraí, RS. Revista Brasileira de Ciência do Solo, v.31, p.1205-1217, 2007.

Bazzano, M. G. P.; Eltz, F. L. F.; Cassol, E. A. Erosividade e características hidrológicas das chuvas de Rio Grande (RS). Revista Brasileira de Ciência do Solo, v.34, p.235-244, 2010.

Bertoni, J.; Lombardi Neto, F. Conservação do solo. 2.ed.São Paulo: Ícone, 1990. 355p.

Campos Filho, O. R.; Silva, I. de F.; Andrade, A. P. de; Leprun, J. C. Erosividade da chuva e erodibilidade do solo no Agreste de Pernambuco. Pesquisa Agropecuária Brasileira, v.27, p.1363-1370. 1992.
Carvalho, D. F.; Cruz, E. S.; Marinaldo, F. P.; Silva, L. D. B.; Guerra, J. G. M. Características da chuva e perdas por erosão sob diferentes práticas de manejo do solo. Revista Brasileira de Engenharia Agrícola e Ambiental, v.13, p.3-9, 2009.

Carvalho, M. P.; Freddi, O. S.; Veronese, V. Critérios de classificação de chuva individual erosiva para o Estado de São Paulo. Acta Scientiarum, v.26, p.175-183, 2004.

Carvalho, N. O. Hidrossedimentologia prática. 2.ed. Rio de Janeiro: Interciência, 2008. 599p.

Cassol, E. A.; Eltz, F. L. F.; Martins, D.; Lemos, A. M.; Lima, V. S.; Bueno, A. C. Erosividade, padrões hidrológicos, período de retorno e probabilidade de ocorrência das chuvas em São Borja, RS. Revista Brasileira de Ciência do Solo, v.32, p.1239-1251, 2008.

Cassol, E. S.; Martins, D.; Eltz, F. L. F.; Lima, V.S.; Buenos, A. C. Erosividade e padrões hidrológicos das chuvas de Ijuí (RS) no período de 1963 a 1993. Revista Brasileira de Agrometeorologia, v.15, p.220-231, 2007.

Chaves, I. B.; Leite Júnior, G. P.; Maia Neto, F. F. Análise da pluviometria e da erosividade das chuvas de Patos (PB). In: Congresso Brasileiro de Ciência do Solo, 26, 1997, Rio de Janeiro. Anais... Rio de Janeiro: SBCS, 1997. CD-Rom

Colodro, G.; Carvalho, M. P.; Roque, C. G.; Prado, R. M. Erosividade da chuva: Distribuição e correlação com a precipitação pluviométrica de Teodoro Sampaio (SP). Revista Brasileira de Ciência do Solo, v.26, p.809-818, 2002.

Dias, A. S.; Silva, J. R. C. A erosividade das chuvas em Fortaleza (CE). I Distribuição, probabilidade de ocorrência e período de retorno - 1a. Aproximação. Revista Brasileira de Ciência do Solo, v.27, p.335-345, 2003.

Foster, G. R.; Mc Cool, D. K.; Renard, K. G.; Moldenhauer, W. C. Conversion of the universal soil loss equation to SI metric units. Journal of Soil Water Conservation, v.36, p.355-359, 1981.

Horner, W.W.; Jens, S.W. Surface runoff determination from rainfall without using coefficients.Transactions of the ASAE, v.107, p.1039-1117, 1942.

Lombardi Neto, E. Rainfall erosivity distribution and relationship with soil loss in Campinas, Brasil. West Lafayette: Purdue University, 1977. 53p. Master's Dissertation

Lopes, P. C. R.; Brito, L. T. L. Erosividade da chuva no Médio São Francisco. Revista Brasileira de Ciência do Solo, v.17, p.129-133. 1993.

Machado, R. L.; Carvalho, D. F.; Costa, J. R.; Oliveira Neto, D. H.; Pinto, M. F. Análise da erosividade das chuvas associada aos padrões de precipitação pluvial na região de Ribeirão das Lajes (RJ). Revista Brasileira de Ciência do Solo, v.32, p.2113-2123, 2008.

Maia Neto, F. F.; Chaves, I. B. Mapeamento da erosividade das chuvas da Paraíba. In: Congresso Brasileiro de Ciência do Solo, 26, 1997, Rio de Janeiro. Anais... Rio de Janeiro: SBCS, 1997. CD-Rom

Margolis, E.; Silva, A. B.; Jacques, F. O. Determinação dos fatores da equação universal das perdas de solo para as condições de Caruaru (PE). Revista Brasileira de Ciência do Solo, v.9, p.165-169, 1985. 
Mazurana, J.; Cassol, E. A.; Santos, L. C.; Eltz, F. L. F.; Bueno, A. C. Erosividade, padrões hidrológicos e período de retorno das chuvas erosivas de Santa Rosa (RS). Revista Brasileira de Engenharia Agrícola e Ambiental, v.13, p.975-983, 2009.

Mehl, H. U.; Eltz, F. L. F.; Reichert, J. M.; Didoné, I. A. Caracterização dos padrões de chuva ocorrentes em Santa Maria (RS). Revista Brasileira de Ciência do Solo, v.25, p.475483, 2001.

Mello, C. R.; Sá, M. A. C.; Curi, N.; Mello, J. M.; Viola, M. R.; Silva, A. M. Erosividade mensal e anual da chuva no Estado de Minas Gerais. Pesquisa Agropecuária Brasileira, v.42, p.537-545, 2007.

Montenegro, A. A. A.; Montenegro, S. M. G. L. Variabilidade espacial de classes de textura, salinidade e condutividade hidráulica de solos em planície aluvial. Revista Brasileira de Engenharia Agrícola, v.10, p.30-37, 2006.

Moreti, D.; Mannigel, A. R.; Carvalho, M. P. Fator erosividade da chuva para o município de Pedrinhas Paulista, Estado de São Paulo. Acta Scientiarum: Agronomy, v.25, p.137-145, 2003.

Rufino, R. L.; Biscaia, R. C. M.; Merten, G. H. Determinação do potencial erosivo da chuva do Estado do Paraná, através de pluviometria: terceira aproximação. Revista Brasileira de Ciência do Solo, v.17, p.439-444, 1993.

Santos, T. E. M.; Montenegro, A. A. A.; Pedrosa, E. M. R. Características hidráulicas e perdas de solo e água sob cultivo do feijoeiro no semi-árido. Revista Brasileira de Engenharia Agrícola e Ambiental v.13, p.217-225, 2009.
Santos, T. E. M.; Silva, D. D.; Montenegro, A. A. A. Temporal variability of soil water content under different surface conditions in the semiarid region of the Pernambuco State. Revista Brasileira de Ciência do Solo, v.34, p.1733-1741, 2010.

SECTMA - Secretaria de Ciência, Tecnologia e Meio Ambiente. Atlas de bacias hidrográficas de Pernambuco. 1.ed. Recife: Secretaria de Ciência, Tecnologia e Meio Ambiente, 2006. $104 \mathrm{p}$.

Silva, A. P. N.; Montenegro, A. A. A.; Moura, G. B. A.; Silva, J. R. L. Variações nos elementos meteorológicos no município de Pesqueira-PE: indícios de possíveis alterações no clima. In: Conferência Internacional sobre Água em Regiões Áridas e Semiáridas, 2, 2007, Gravatá, Anais... Porto Alegre: ABRH, 2007. CD-Rom

Silva, I. F.; Andrade, A. P. de; Campos Filho, O. R.; Souza, V. F. de. Erosividade das chuvas das zonas fisiográficas Agreste e Sertão de Pernambuco. Agropecuária Técnica, v.6, p.2637, 1985.

Srinivasan, V. S.; Galvão, C. O. Bacia Experimental de Sumé: Descrição e dados coletados. Campina Grande: UFCG/CNPq, 2003. 129p.

Wischmeier, W. H. Storms and soil conservation. Journal of Soil and Water Conservation, v.17, p.55-59, 1962.

Wischmeier, W. H.; Smith, D. D. Predicting rainfall erosion losses: A guide to conservation planning. Washington: US Department of Agriculture, 1978. 58p. Agriculture Handbook, n.537. 